\title{
Adhesion Molecules of Cultured Hematopoietic Malignancies \\ A Calcium-dependent Lectin Is the Principle Mediator of Binding to the High Endothelial Venule of Lymph Nodes
}

\author{
Lloyd M. Stoolman and Hazel Ebling \\ Department of Pathology, University of Michigan School of Medicine, Ann Arbor, Michigan 48109-0602
}

\begin{abstract}
This study documents that a calcium-dependent phosphomannosyl-binding site on human lymphoid malignancies mediates attachment to the peripheral node high endothelial venule (PNHEV). The phorbol ester PMA coordinately upregulates lectin activity and binding to the PNHEV in the human T-lymphoblastic cell line Jurkat but not in the less phenotypically mature lines HSB2, Molt4, CEM, and HPB-ALL. In contrast, expression of CD18, CD2, and several common epitopes of the putative adhesion receptor $\mathrm{gp} 90^{\text {Hermes }}$ (CD44) did not correlate with attachment to PNHEV in this series of cell lines. Insensitivity to inhibition by the CD18 MAb TS 1.18, temperature and divalent cation requirements further distinguish the JurkatPNHEV adhesive interaction from CD11a/18- and CD2-mediated adhesion. The PMA-induced phenotypic changes in the Jurkat line parallel late thymocyte differentiation as well as lymphocyte activation, suggesting that expression of the endothelial-binding lectin may be linked to one or both of these processes. The lectin-like activity on Jurkat cells is functionally indistinguishable from those previously linked to PNHEV recognition in normal human lymphocytes, normal rat lymphocytes and both normal and malignant murine lymphoid cells. In the mouse, this activity is either contained in or functionally linked to a member of the LEC-CAM family gp90 ${ }^{\text {Mel14}}$, suggesting that Jurkat cells express the human homologue of the murine nodal homing receptor. Thus cultured $T$ lymphoblastic malignancies express a variety of potential endothelial adhesion molecules but use primarily a highly conserved surface lectin to interact with PNHEV.
\end{abstract}

\section{Introduction}

The trafficking of normal and malignant lymphocytes into tissues begins with the binding of cells to postcapillary endothelium. In lymph nodes, submucosal lymphoid tissues and many chronic inflammatory lesions, this endothelium develops unique characteristics that facilitate the arrest of circulating cells. In particular, the lumenal surface area increases dramatically and specific adhesion sites are expressed. The resulting structure, termed high endothelial venule (HEV), ${ }^{1}$ is the histologic hallmark of active lymphocyte migration (1-3).

Address reprint requests to Dr. Lloyd Stoolman, Department of Pathology, University of Michigan, 1301 Catherine Rd., Ann Arbor, MI 48109-0602. 1989.

Received for publication 21 April 1989 and in revised form 14 June

1. Abbreviations used in this paper: HEV, high endothelial venule; HUVEC, human umbilical vein endothelium; PN, peripheral node;

J. Clin. Invest.

(C) The American Society for Clinical Investigation, Inc.

0021-9738/89/10/1196/10 \$2.00

Volume 84, October 1989, 1196-1205
Functionally distinct lymphoid adhesion receptors have been described for the HEV of several target organs $(4,5)$. In the human, 85-95- and 200-kD monomeric glycoproteins of the Hermes/CD44 family have been linked to endothelial binding in peripheral nodes, gut-associated lymphoid tissues (GALT) and rheumatoid synovium (6-8). In the murine system, an 85-95-kD monomeric glycoprotein (Mel14 antigen or gp90 ${ }^{\text {Mel14 }}$ ) mediates attachment of normal and malignant lymphoid cells to nodal HEV $(5,6)$. Recently, Holzman et al. have identified a 160/130-kD heterodimer on murine lymphocytes (Lpam 1) that supports selective binding to the HEV of Peyer's patches and cross-reacts with human VLA4 alpha chain-specific MAbs (9). In the rat, two glycoproteins, termed $\mathrm{HEBF}_{\mathrm{ln}}$ and $\mathrm{HEBF}_{\mathrm{pp}}$, have been isolated from lymph with the functional characteristics of shed organ-selective adhesion structures (10). The partially purified glycoproteins interact with HEV to inhibit attachment to target organs, whereas polyclonal and monoclonal antibodies to these factors inhibit only after binding to lymphocytes. In rodents, MAbs that block lymphocyte attachment to $\mathrm{HEV}$ in vitro inhibit organ-selective lymphocyte homing in vivo. Thus, organ-selective adhesion structures on lymphoid cells are commonly referred to as homing receptors. Finally, the lymphocyte functional antigen (LFA1;CD1 1a/18) enhances homing receptor-mediated binding to HEV (11) and initiates non-tissue-specific attachment to activated endothelium (12-14).

As predicted by the lymphocyte studies, venular endothelium appears to express both selective and multipurpose adhesion determinants. Streeter et al. have linked two antigenically distinct sites on murine HEV to lymphocyte adhesion $(15,16)$. Specifically, the HEV-specific MAb MECA 79 blocks binding to and migration across peripheral node HEV (PNHEV), whereas MAb MECA 367 has a similar effect on Peyer's patch HEV. ICAM-1, a widely distributed ligand for CD1 1a/18, has been identified as one of at least three lymphocyte attachment sites on human umbilical vein endothelium (HUVECs) and fibroblast $(13,14)$. Expression of ICAM-1 and lymphocyte attachment to HUVECs increase in parallel after treatment with IL 1 , tumor necrosis factor, or $\gamma$-IFN, suggesting that LFA 1-ICAM-1 interactions may augment lymphocyte migration in chronic inflammatory lesions. Thus, lymphocyte-endothelial attachment in vivo involves the concerted action of organ-selective and multipurpose adhesion structures on the interacting cells.

Independent studies by the author suggest that a lectin-like structure on the lymphocyte surface constitutes the peripheral node homing receptor (17-19). In the rat, mouse, and human, functionally similar calcium-dependent phosphomannosylbinding sites on intact cells have been linked to recognition of peripheral lymph node HEV (PNHEV). In the murine system,

PNHEV, peripheral node high endothelial venule; PPME, polyphosphomonoester core from Hansenula holstii phosphomannan. 
this site is either contained in or intimately associate with gp90 $90^{\text {Mel14 }}(20,21)$. Sequence analysis of murine gp $90^{\text {Mell } 4}$ reveals a novel structure notable for an $\mathrm{NH}_{2}$-terminus, extracellular domain homologous to a variety of calcium-dependent (C-type) animal lectins, further supporting the hypothesis that a protein-carbohydrate interaction mediates homing to peripheral lymph nodes $(22,23)$. The endogenous ligand for the lectin has not been identified; however, terminal sialic acid residues appear critical since desialation of murine HEV blocks endothelial attachment and migration in lymph nodes but not in Peyer's patches $(24,25)$. In all species and cell lines tested to date, lectin activity correlates directly with affinity for PNHEV indicating evolutionary conservation of both the carbohydrate- and endothelial-binding domains.

This study examines the regulation of PNHEV and carbohydrate binding activities on the cell surface of cultured human leukocytic malignancies. Both were dramatically upregulated during PMA-induced differentiation/activation of the Jurkat cell line. In contrast, several less mature $T$ lymphoblastic lines, an erythroblastic and a histiocytic line showed neither constitutive nor inducible binding activities. The lectin-like activity on Jurkat cells is functionally indistinguishable from that of normal peripheral blood lymphocytes and distinct from LFA1, CD2, and the $\mathrm{gp} 90^{\text {Hermes }}$ (CD44) antigens. Thus cultured human hematopoietic malignancies use an endothelial binding lectin as a principle PNHEV recognition molecule. Moreover, the effect of PMA in the Jurkat line suggests that signaling through protein kinase $\mathrm{C}$ dependent pathways modulate endothelial recognition, in part, through actions on lectin activity.

\section{Methods}

Chemicals. PMA (P8139), heparin (H3125), chondroitin sulfate (C3254), hyaluronic acid (H7630), all phosphorylated monosaccha- rides, BSA (A7906), borax (B9876), boric acid (B0252), cyanogen bromide (C6388), cacodylic acid (C0250), disodium EDTA (ED2SS), poly-L-lysine (P1524), clostridial neuraminidase (N2133), and paraformaldehyde (P6148) were obtained from Sigma Chemical Co. (St. Louis, MO). PPME, the polyphosphomonoester core from Hansenula holstii phosphomannan, was the generous gift of Dr. M. E. Slodki (U.S. Department of Agriculture, Northern Regional Research Center, Peoria, IL). Florescent microspheres (0.6- $\mu \mathrm{m}, \mathrm{FX}, 112030-30)$, were obtained from Duke Scientific (Palo Alto, CA). MEM (330-1435) and tricine (845-1398) were purchased from Gibco Laboratories (Grand Island, NY). Powdered FA buffer was obtained from Difco Laboratories (Detroit, MI). T series, mouse anti-human MAbs were obtained from Coulter Electronics (Hialeah, FL); the Leu-series reagents were purchased from Becton-Dickinson \& Co. (Palo Alto, CA). MAb TS1.18 (CD18; LFA1 beta chain epitope; mouse anti-human IgG) was provided by Dr. A. Krensky and Dr. C. Clayberger (Department of Pediatrics, Stanford University School of Medicine, Palo Alto, CA). The Hermes 1 monoclonal (rat anti-human IgG), Hermes 3 monoclonal (mouse anti-human IgG), and polyclonal Hermes (mouse antihuman unfractionated serum) were provided by Dr. Eugene C. Butcher (Department of Pathology, Stanford University School of Medicine).

Cell culture. Surface marker (Table I) and gene rearrangement studies (data not shown) were conducted to verify that the $T$ lymphoblastic cell lines conformed to published characteristics (26-31). Cells were grown in RPMI 1640 medium (Gibco Laboratories) supplemented with 5-10\% fetal bovine serum, glutamine, penicillin and streptomycin. Cell densities were maintained between 3 and $20 \times 10^{5}$ cells $/ \mathrm{ml}$. Cell lines were treated with three courses of BM-cycline (Boehringer Mannheim Biochemicals, Indianapolis, IN) and assayed for mycoplasma contamination before use. All lines were mycoplasma free after treatment.

Fractionation of peripheral blood. Mononuclear cells were prepared from EDTA-anticoagulated peripheral blood using a discontinuous gradient of coloidal silica in Hepes-buffered saline (SepracellMN; Sepratech Corp., Oklahoma City, OK). In brief, equal volumes of anticoagulated whole blood and Sepracell-MN were thoroughly mixed

Table I. Expression of Cell-Surface Antigens in Native and PMA-stimulated T Lymphoblastic Cell Lines

\begin{tabular}{|c|c|c|c|c|c|c|c|c|c|c|}
\hline Line & PMA & $\mathrm{CD} 1$ & $\mathrm{CD} 2$ & $\mathrm{CD} 3$ & CD4 & CD5 & CD8 & T9 & L9 & $\mathrm{CD} 18$ \\
\hline \multirow{3}{*}{ Jurkat } & UT & 2.4 & 11.6 & 4.1 & 2.1 & 2.9 & 2.1 & 3.7 & 3.2 & 1.9 \\
\hline & $72 \mathrm{~h}$ & 1.0 & 24.0 & 1.3 & 1.3 & 7.6 & 1.1 & 1.3 & 1.3 & 1.9 \\
\hline & $144 \mathrm{~h}$ & 1.3 & 52.3 & 2.5 & 1.0 & 15.1 & 1.0 & 1.3 & 1.3 & 3.7 \\
\hline \multirow[t]{3}{*}{ HPB-ALL } & UT & 2.0 & 2.3 & 2.3 & 4.9 & 9.8 & 4.1 & ND & ND & 2.2 \\
\hline & $72 \mathrm{~h}$ & 1.5 & 1.2 & 2.1 & 2.2 & 9.0 & 1.7 & ND & ND & 4.1 \\
\hline & $144 \mathrm{~h}$ & 1.0 & 2.5 & 9.5 & 1.9 & 16.0 & 9.2 & ND & ND & 4.8 \\
\hline \multirow[t]{2}{*}{ CEM } & UT & 1.3 & 5.0 & 1.2 & 6.0 & 10.1 & 2.1 & 55.4 & 27.7 & 6.9 \\
\hline & $96 \mathrm{~h}$ & 1.1 & 5.8 & 4.8 & 1.7 & 14.3 & 1.9 & 11.3 & 12.3 & 6.0 \\
\hline \multirow[t]{2}{*}{ Molt 4} & UT & 3.1 & 8.5 & 1.0 & 1.4 & 7.3 & 1.4 & 14.3 & 3.4 & 1.9 \\
\hline & $96 \mathrm{~h}$ & 1.7 & 21.4 & 1.0 & 1.1 & 14.7 & 1.5 & 3.0 & 1.2 & 3.0 \\
\hline \multirow[t]{2}{*}{ HSB-2 } & UT & 1.1 & 1.5 & 1.0 & 1.0 & 6.0 & 1.4 & 6.0 & 4.8 & ND \\
\hline & $96 \mathrm{~h}$ & 1.0 & 1.2 & 1.1 & 1.1 & 11.3 & 1.7 & 2.1 & 3.6 & ND \\
\hline \multirow[t]{2}{*}{ PBMC } & MEAN & 1.1 & 4.3 & 4.2 & 4.0 & 2.8 & 4.6 & 1.1 & 1.5 & 3.2 \\
\hline & SD & 0.1 & 1.8 & 1.2 & 1.7 & 0.3 & 2.4 & 0.2 & 0.3 & 2.1 \\
\hline
\end{tabular}

The cell lines were grown in RPMI supplemented with $50 \mathrm{nM}$ PMA for 72, 96, or $144 \mathrm{~h}$, then examined for expression of T cell antigens. UT, antigen expression in native (untreated) cell lines. The numbers given in the table are the mean linear fluorescence of 5,000 cells normalized to nonspecific fluorescence as described in "Surface markers" under Methods (termed MLF). An MLF of 1 indicates that no antigen was detected above background, whereas an MLF of 52 indicates that antigen was present and the fluorescent signal was 52-fold higher than background. The values given are representative of two to four independent marker assays. The means and SEM for the PBMC controls run in parallel are presented for comparison. 
and centrifuged at $1,500 \mathrm{~g}$ for $20 \mathrm{~min}$ at room temperature. Mononuclear cells were subsequently separated from contaminating platelets by three to four $200-g$ wash steps using calcium, magnesium-free PBS supplemented with $1 \mathrm{mg} / \mathrm{ml}$ BSA. After the final wash, cells were resuspended in the appropriate assay buffer.

Surface marker assays. Indirect immunofluorescence assays for $\mathrm{T}$ cell differentiation antigens were conducted in microtiter plates as follows. Antigen-specific mouse anti-human MAbs $(50 \mu \mathrm{l})$ were combined with cells $\left(2.5 \times 10^{5}\right.$ in $\left.50 \mu \mathrm{l}\right)$ and incubated at $4^{\circ} \mathrm{C}$ for $30 \mathrm{~min}$ in FA buffer supplemented with $1 \%$ fetal bovine serum and $0.05 \% \mathrm{Na}$ azide (subsequently referred to as FA+). Cells were washed twice in FA+ $(200 \mu \mathrm{l})$, resuspended and combined with $50 \mu \mathrm{l}$ of FITC-labeled goat anti-mouse IgG ( $\mathrm{Fab}_{2}$ fragments, Cappel Laboratories, West Chester, PA) for an additional $30 \mathrm{~min}$ at $4^{\circ} \mathrm{C}$. After three washes in FAt, pellets were resuspended and combined with $200 \mu \mathrm{l}$ of $1-2 \%$ paraformaldehyde before cytometric analysis. Both primary and secondary antibodies were used at saturating concentrations.

The mean linear fluorescence (MLF) for each marker and control were determined in 5,000 cell samples using a cytometer (FACS Epics V; Coulter Electronics). The signals from all cells (positives and negatives) were included in the determination so that changes in both the percentage of cells expressing a given marker and antigen density were reflected in the sample mean. In Table I, the MLFs for each marker are normalized to that for nonspecific fluorescence, which is arbitrarily set to 1. A 25-fold excess of pooled mouse IgG (control for T cell markers and Hermes 3 ) or pooled rat IgG (control for rat anti-human Hermes 1) and an equal dilution of unfractionated mouse serum (control for polyclonal Hermes antisera) were used in the primary incubation to quantitate nonspecific fluorescence. This data reduction protocol enables one to readily quantitate and summarize changes in marker expression resulting from cell treatment. It does not, however, enable one to distinguish between changes in antigen density or the percentage of cells expressing antigen. For example, in Table I the MLF for CD2 in native (untreated) Jurkat cells is 12 . It increased to 52 after 144 $h$ of treatment with PMA, reflecting a $51 / 12$ or $\sim 4.8$-fold increase in mean fluorescence for the population. This reflects both an increase in the antigen density and in the percentage of cells expressing antigen.

HEV binding assay. The HEV of human, rat, murine, and guinea pig lymphoid organs express functionally indistinguishable organ-selective adhesion structures $(19,32)$. Therefore, one can quantitate expression of HEV-binding molecules on human cells using rodent HEV as targets. This study used a modified Stamper-Woodruff assay to quantitate the attachment of lymphoid cells to rat PNHEV as described previously (19). In brief, 1-6 $\times 10^{5}$ neuraminidase-treated $\left(0.005 \mathrm{U} / \mathrm{ml}, 37^{\circ} \mathrm{C}, 30 \mathrm{~min}\right)$, human PBMC and/or cultured malignant lines were applied to paraformaldehyde-fixed, frozen sections of rat cervical lymph nodes and gyrated $(60 \mathrm{rpm})$ at $7-10^{\circ} \mathrm{C}$ for $30 \mathrm{~min}$. The cell suspensions were then gently decanted, the sections were fixed in glutaraldehyde (3\% in PBS, $20 \mathrm{~min}, 4^{\circ} \mathrm{C}$ ), stained with toluidine blue and analyzed by light microscopy. The average number of cultured cells bound to HEVs per $200 \times$ microscopic field was normalized to the level of attachment measured in concurrently run PBMC or native cultured cells. SEM for this procedure varied from 10 to $30 \%$.

PPME-bead assay. The conjugation of PPME, the polyphosphomonoester core polysaccharide derived from the yeast Hansenula holstii, to fluorescent microspheres and the procedure for measuring the attachment of conjugated beads to lymphocytes has been presented in detail elsewhere (19-21). In brief, the free amino groups on $0.5-0.7-\mu \mathrm{m}$ fluorescent microspheres (FX-beads, Duke Scientific) were derivitized with cyanogen bromide-activated PPME at pH 8.0 in $0.2 \mathrm{M}$ borate buffer for 2-12 h. After blockade of unreacted cyanate groups with 0.1 $M$ glycine, the beads were aliquoted, snap-frozen in liquid nitrogen, and stored at $-70^{\circ} \mathrm{C}$ until use. Beads prepared in this manner may not withstand long-term storage; therefore, experiments were conducted with freshly thawed aliquots within 7-10 d of preparation.

Before use, the beads were sonicated to disrupt clumps, washed, and resuspended in assay buffer. Beads and cells were combined in flat-bottomed, 96-well microtiter plates ( $200 \mu$ l final volume; $5 \times 10^{6}$ cells, beads diluted $1: 16$ or $1: 32$ relative to stock solution), centrifuged and incubated for $60 \mathrm{~min}$ on ice. After gentle resuspension, cells with attached beads were either fixed immediately or separated from free beads by centrifugation through a $6 \%$ BSA gradient before fixation in $1 \%$ paraformaldehyde.

Cell-associated fluorescence was quantified on a FACS as described (19). The endothelial-binding lectin is calcium-dependent, therefore, its activity was distinguished from cation-independent phosphomannan receptors and quantitized by subtracting the MLF measured in the presence of $5 \mathrm{mM}$ EDTA from that measured in buffer alone (19-21). A unitless measure of calcium-dependent binding activity, the percentage of positive cells multiplied by the specific MLF, was calculated for each experimental condition and then normalized to control populations run in parallel. Thus data points reflect the percentage of cells with calcium-dependent PPME binding sites as well as the density and avidity of the individual receptors (19).

Phorbol treatment of cultured lines. Cell lines were treated with PMA at final concentrations varying from 1 to $50 \mathrm{nM}$ and an initial cell concentration of $1-3 \times 10^{5}$ cells $/ \mathrm{ml}$ in growth medium. Stocks $(0.5$ $\mathrm{mM}$ ) were prepared in $100 \%$ DMSO, aliquoted, and stored at $-20^{\circ} \mathrm{C}$. New stocks were prepared every 1-2 mo. Immediately before treatment, aliquots were thawed, serially diluted first in $100 \%$ DMSO $(1: 10)$ followed by growth medium (1:100), filter sterilized and added directly to freshly diluted cell suspensions in stationary or spinner cultures (250-ml flasks, Techne, Cambridge, UK). This methodology ensured maximal activity of PMA.

\section{Results}

The interaction of $\mathrm{T}$ lymphoblastic (Jurkat, HPBALL,CCRF-CEM, CCRF-Molt4, HSB2), a true histiocytic (U937) and an erythroblastic (K562) cell line with frozen sections of rat peripheral lymph nodes were examined using the modified Stamper-Woodruff assay. All lines bound to germinal center and sinusoidal lining cells to varying degrees; however, only the Jurkat line attached to PNHEV in paraformaldehyde-fixed sections (Fig. 1). Affinity for PNHEV ranged from $0-200 \%$ (mean $50 \%$ ) that of normal peripheral blood lymphocytes run in parallel (Fig. 2). The range in measured affinities does not reflect differences in culture viability because trypan blue exclusion exceeded $90-95 \%$ in all experiments. Thus a human $\mathrm{T}$ lymphoblastic cell line with the surface marker characteristics of a mid-late thymic $T$ cell attached to PNHEV. In contrast, several other less phenotypically mature $\mathrm{T}$ lymphoblastic lines and lines of macrophage or erythroid origin failed to bind.

The relationship between differentiation, activation, and affinity for PNHEV in the T lymphoblastic lines was examined further using PMA. The nature, pace, and extent of the phenotypic changes induced by this potent activator of protein kinase $\mathrm{C}$ depended on the characteristics of the native line (Table I and 26-29). As previously reported $(30,31)$, all lines showed clonal rearrangements of the alpha and beta $T$ cell receptor genes (data not shown). The native HSB-2 line expressed pan-T antigens exclusively thus resembled thymic precursor/stage 1 thymocytes. The native Molt4, CEM, and HPB-ALL lines resembled stage 1-2 thymocytes expressing pan-T antigens plus one or more of the following: CD1(T6), CD3(T3), CD4(T4), and CD8(T8). The native Jurkat line resembled a stage 2-3 thymocyte with relatively high levels of all pan- $T$ antigens, $C D 3, C D 4, C D 1$, and the antigen receptor (WT31-data not shown). CD8 was intermittently detected in the native line. Phorbol stimulation upregulated expression of CD3 in two lines (CEM and HPB) and CD5 in all cases. In 


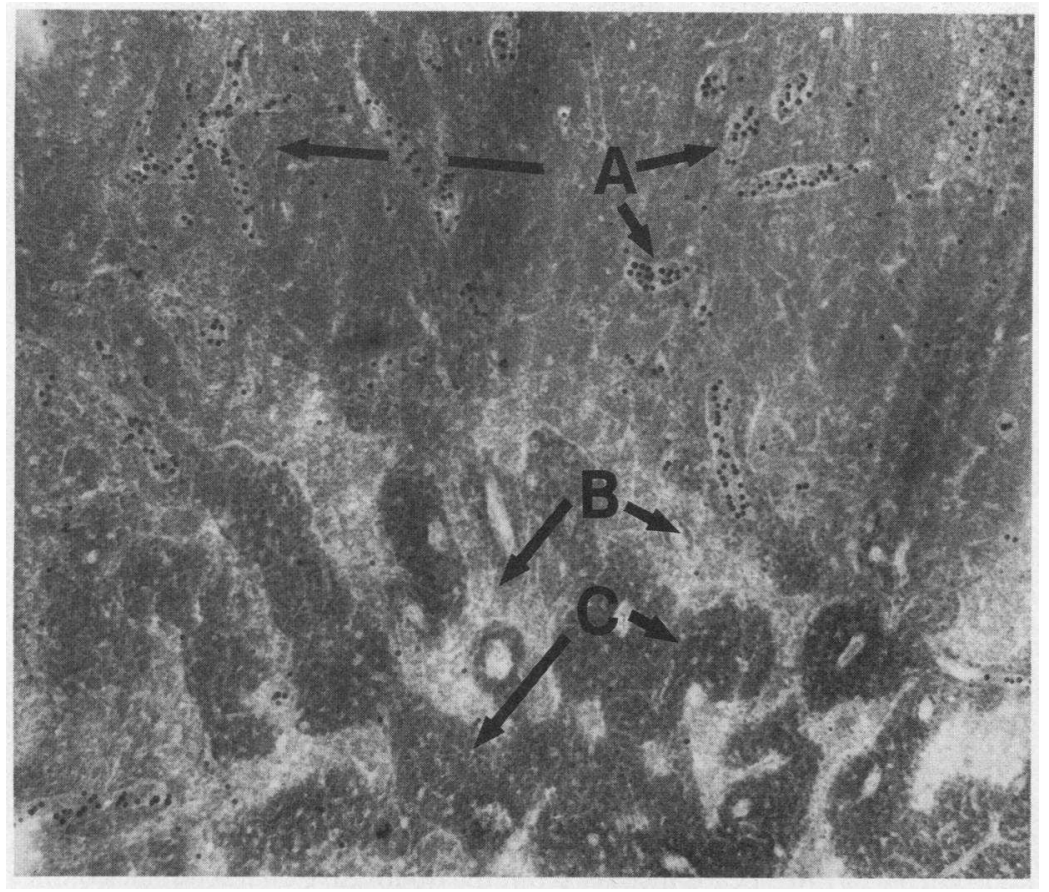

Figure 1. Photomicrograph of native Jurkat cell line binding to the HEV of rat peripheral lymph node. Jurkat cells overlay numerous HEV $(A)$ in the diffuse cortex of the node but not the surrounding lymphocyte-rich areas, the macrophage-rich sinusoids $(B)$, or the plasma cellrich medullary cords $(C)$. All $\mathrm{T}$ lymphoblastic lines examined showed variable binding to sinusoids and germinal centers, particularly when the cell concentration exceeded $5 \times 10^{6} / \mathrm{ml}\left(6 \times 10^{5}\right.$ cell/section $)$ in the assay. Only the Jurkat line bound significantly to the HEV. addition, expression of CD4 diminished in the four CD4/CD8 double-positive cell lines (Molt4, CEM, HPB, and Jurkat) along with $\mathrm{CD} 1$ and $\mathrm{T} 9$ (the transferrin receptor). Thus, all T lymphoblastic lines demonstrated, to varying degrees, phenotypic changes indicative of thymic differentiation (33).

In addition, PMA treatment enhanced expression of $\mathrm{CD} 2$ (Molt4 and Jurkat) and CD18 (Molt4, HPB, and Jurkat). In Jurkat cells, the LFA1 appeared to be functional because PMA-induced autoaggregation was completely blocked by the CD18, beta chain-specific Mab TS1.18 (data not shown). Finally, the Jurkat line was unique in that surface expression of CD3 decreased in response to PMA. The downregulation of both $\mathrm{CD} 3$ and $\mathrm{CD} 4$ antigens has been reported in mature lymphocytes during mitogen-, antigen-, and phorbol-induced activation (34-36). CD2 and LFA-1, furthermore, are coordinately increased after mitogen-stimulation of cord-blood lymphocytes (37). Thus PMA treatment, particularly in the Jurkat cell line, resulted in phenotypic changes consistent with both activation and differentiation.

PMA produced a dramatic increase in the affinity of Jurkat cells for PNHEV (Fig. 2). In contrast, the other lines did not respond in this manner. Induction occurred at or above a PMA concentration of $1 \mathrm{nM}$. The in vitro assay best reflected the increase in affinity under conditions that stressed the adhesive interaction. Reducing the number of cells per section during the assay or increasing the number of washes after glutaraldehyde fixation thus increased the measured difference between PMA-treated Jurkat cells and controls (Fig. 3). Five to sixfold increases in binding relative to untreated Jurkat cells or PBMC were detected under these conditions. The precise incubation time for maximal induction varied considerably in different experiments. This may reflect the lability of PMA in aqueous solution or differences in the cellular response. In general, maximal induction occurred when cells were freshly diluted to $1-3 \times 10^{5}$ cells $/ \mathrm{ml}$ before treatment. Under these conditions, induction required a minimum of $48-72 \mathrm{~h}$ incubation with peak effects $72-144 \mathrm{~h}$ into treatment.
Previous work demonstrated that an EDTA-sensitive, lectin-like structure on normal human lymphocytes mediated attachment to PNHEV in vitro (19). We, therefore, quantitated lectin activity on both native and phorbol-treated cell lines (Fig. 4). PPME-beads were used to quantitate lectin activity. Only the Jurkat line demonstrated significant constitutive and phorbol-inducible EDTA-sensitive bead attachment. Furthermore, lectin activity and affinity for PNHEV increased in parallel when measured concurrently in Jurkat cells (Fig. 5). In the experiment depicted, both lectin activity and binding to PNHEV rose sixfold relative to untreated Jurkat cells between 48 and $72 \mathrm{~h}$ of incubation.

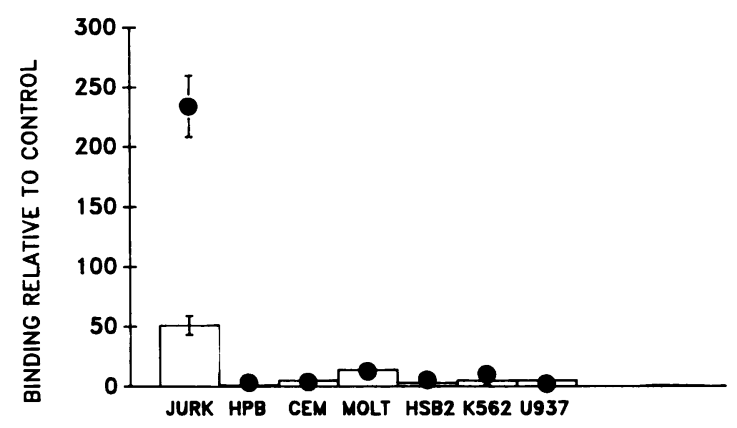

Figure 2. Binding of hematopoetic cell lines to the HEV of rat peripheral lymph node. Lines were grown in RPMI supplemented with either PMA (1-50 nM) or DMSO (0.002-0.10\%, control for residual DMSO used to solubilize the PMA) for $>72 \mathrm{~h}$ as described in "Phorbol treatment" in Methods. DMSO alone had no effect on the growth, viability, or affinity for HEV. PMA treatment slowed growth in several cell lines and gradually reduced cell viability as reported previously $(55,27,28)$. Clear bars, binding after treatment with DMSO; solid circles, level of binding after treatment with PMA. Mean and SEM (error bars) calculated after pooling data from 2-11 individual experiments each consisting of four replicate samples per data point. SEM for all lines except Jurkat were $<10 \%$. 


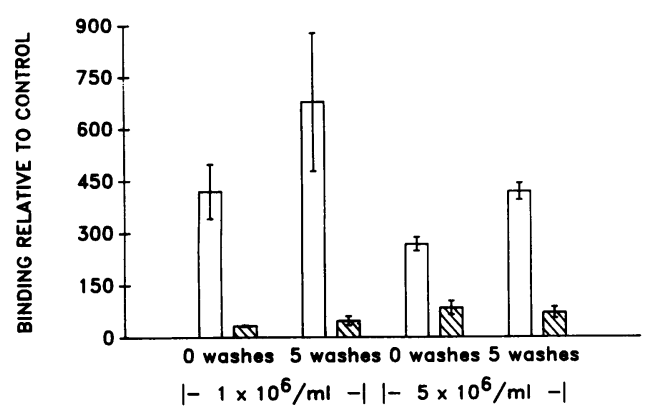

Figure 3. Effect of wash conditions and cell concentration on the binding of PMA-treated Jurkat cells to rat lymph node HEV. HEV binding assays were conducted at 1 or $5 \times 10^{6}$ cells $/ \mathrm{ml}$ (i.e., 1 or 6 $\times 10^{5}$ cells/section), with or without five dips (washes) in PBS after glutaraldehyde fixation (see "HEV binding assay" in Methods). Clear bars, binding of PMA-treated cells. Cross-hatched bars, binding of DMSO-treated cells.

The time course and peak level of lectin activity differed from experiment to experiment; however, in all cases activity correlated with binding to PNHEV. A causal linkage was suggested by regression analysis of 11 independent experiments in which lectin activity and binding to PNHEV were measured concurrently (Fig. 6). The duration of PMA-treatment in this group varied from 24-144 $\mathrm{h}$. When normalized to freshly prepared PBMC run in parallel, the affinity of lymphocytes for PPME beads and PNHEV showed a positive correlation with a correlation coefficient of 0.88 . Thus the expression of EDTAsensitive, phosphomannosyl-binding activity and affinity for PNHEV in vitro were upregulated in parallel during PMA treatment of Jurkat cells. In contrast, HPB, CEM, Molt4, HSB-2, U937, and K562 lines could not be induced to express either lectin or PNHEV binding activity.

The next series of experiments showed that the lectin activity on Jurkat cells was functionally identical to that of normal PBMC. We have shown previously that brief neuraminidase treatment of normal human PBMC facilitated detection of lectin and PNHEV binding activity without altering the functional characteristics of the adhesive interactions (19). Neuraminidase pretreatment had the same effect on the adhesive

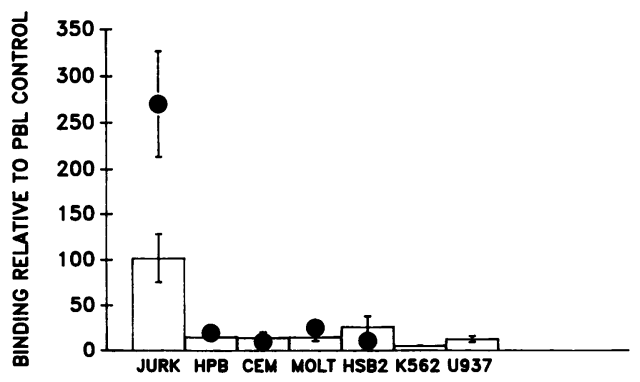

Figure 4. Effect of PMA treatment on expression of the calcium-dependent phosphomannosyl-binding sites (the putative endothelialbinding lectin) on Jurkat cells. These experiments were conducted in parallel with the HEV binding experiments depicted in Fig. 2. After growth in either DMSO or PMA, a portion of the cells were assayed for expression of PPME-bead binding sites as described in "PPMEbead assay" in Methods. Means and SEMs were calculated after pooling data from 2-11 individual experiments each consisting of two replicate samples per data point.

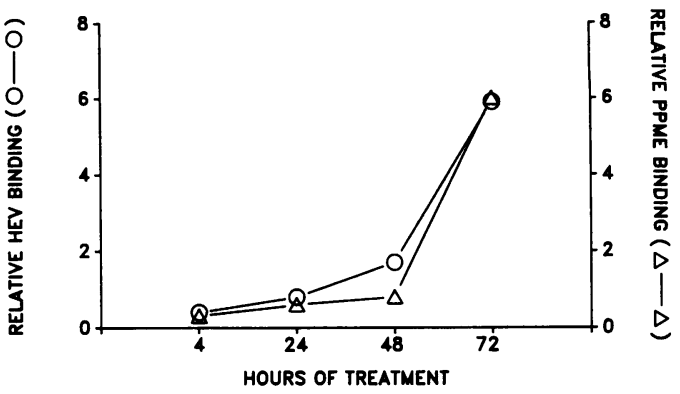

Figure 5. Time course for PMA induction of binding activity. Jurkat cells were placed in RPMI supplemented with either $0.1 \%$ DMSO or $50 \mathrm{nM}$ PMA and sampled at intervals over $72 \mathrm{~h}$. At each time point, affinity for the HEV of rat lymph nodes and for PPME beads were determined and normalized to concurrently run PBMC as described in Methods. The ratio of the normalized binding activities measured for the PMA- and DMSO-treated cultures are plotted for both attachment to the HEV (relative HEV binding) and PPME beads (relative PPME binding).

interactions of Jurkat cells. Baseline binding to both HEV and PPME beads increased but the qualitative characteristics of the interactions were unchanged. Fig. 7 documents the calcium dependence of these adhesive interactions. Binding assays were conducted in assay buffer alone (MEM supplemented with $1 \mathrm{mg} / \mathrm{ml} \mathrm{BSA}$ and $40 \mathrm{mM}$ tricine, $\mathrm{pH} \mathrm{7.3)} \mathrm{or} \mathrm{buffer}$ supplemented with $3 \mathrm{mM}$ EGTA, $3 \mathrm{mM}$ EGTA $+2 \mathrm{mM}$ $\mathrm{CaCl}_{2}$ or $3 \mathrm{mM}$ EGTA $+2 \mathrm{mM} \mathrm{MgCl}$. The assay buffer contained $1.8 \mathrm{mM} \mathrm{CaCl}_{2}$ and $0.8 \mathrm{mM} \mathrm{MgSO}_{4}$ before supplementation. The marked inhibition of binding to HEV and PPME beads in the presence of EGTA, a highly specific chelator of ionized calcium, strongly suggested a strict calcium dependence for the adhesive interactions. Raising the total $\mathrm{CaCl}_{2}$ concentration to $3.8 \mathrm{mM}$ overcame the inhibition by $3 \mathrm{mM}$ EGTA, whereas the addition of 2 or $5 \mathrm{mM}$ (not shown) $\mathrm{MgCl}_{2}$ had no effect confirming the calcium requirement. As previously demonstrated for normal lymphocytes, mannose-6phosphate, soluble PPME and fucoidin were the most potent carbohydrate inhibitors whereas mannose-1-phosphate, hepa-

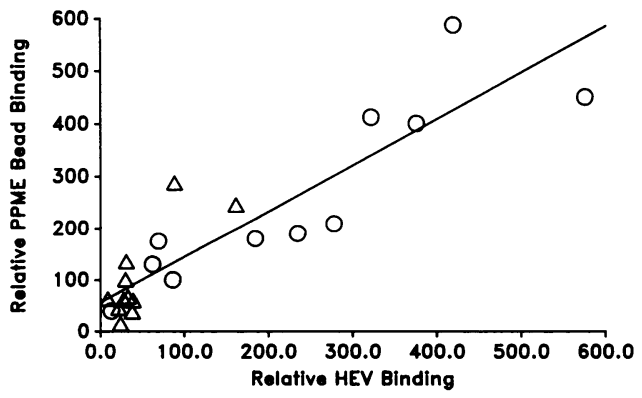

Figure 6. Correlation between binding to PPME beads and HEV. A first-order regression analysis was performed on 21 concurrent measurements of binding to PPME beads and HEV. Both untreated Jurkat cells $(\Delta, n=10)$ and PMA-treated Jurkat cells $(0, n=11)$ were included in the analysis. The means of the HEV assays (four to six replicates) and the PPME bead assays (two replicates) for each cell population were normalized to concurrently run PBMC controls to standardize measurements from independent experiments. The slope of the first-order regression line $(0.88)$ reflects the correlation between affinity for PPME beads and HEV. 

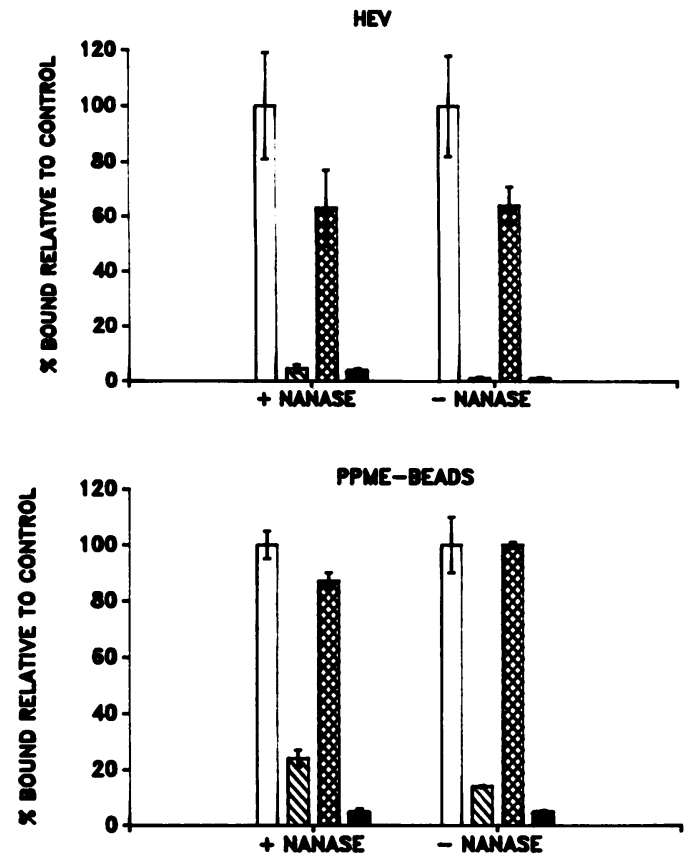

Figure 7. Divalent cation requirements for the binding of PMAtreated Jurkat cells to PPME beads and HEV. Cell suspensions were washed, resuspended, and preincubated $\left(15 \mathrm{~min}, 4^{\circ} \mathrm{C}\right)$ in the respective buffers. $\square$, control; $\mathbb{\otimes}, 3 \mathrm{mM}$ EGTA; $\mathrm{a}, 3 \mathrm{mM}$ EGTA + $2 \mathrm{mM}$ $\mathrm{CaCl}_{2} ;=3 \mathrm{mM}$ EGTA $+2 \mathrm{mM} \mathrm{MgCl}$. The suspensions were then applied to tissue sections or combined with PPME beads as described in the text. Treatment of the Jurkat cells with neuraminidase (NANASE) as described in Methods did not alter the divalent cation requirements.

rin and condroitin sulfate were significantly less effective (Fig. $8 A$ and $B$ ). Calcium-dependent lectin-like receptors thus mediated the attachment of both Jurkat cells and normal human lymphocytes to the HEV of lymph nodes.

Finally, the relationship between lectin activity and gp90 Hermes, an integral membrane structure linked to recognition of nodal, mucosal, and synovial HEV, was examined. Two MAbs, Hermes 1 and 3, and a mouse anti-human polyclonal antisera have been developed to $\mathrm{gp} 90^{\text {Hermes }}(6)$. The monoclonal epitopes were detected on all cell lines except Jurkat (Table II). Phorbol treatment enhanced expression on several cell lines but did not induce expression in Jurkat. The polyclonal Hermes antisera detected low-level expression of Hermes epitopes (15-20-fold lower than concurrently run PBMC) on the Jurkat cell line in one experiment, raising the possibility that a portion of the structure is exposed at the cell surface in low density.

\section{Discussion}

This study demonstrates that the human $\mathrm{T}$ lymphoblastic cell line Jurkat uses a lectin-like structure at the cell surface to interact with PNHEV in vitro. The concurrent upregulation of binding sites for PPME beads and PNHEV during PMA treatment, the correlated expression of these adhesive interactions, their identical divalent cation requirements and sensitivities to carbohydrate inhibition support this conclusion. The lack of lectin and PNHEV binding activities in other leukocytic cell lines indicates that these features are not simply artifacts of long term culture.
Constitutive and phorbol-enhanced expression of binding activity were observed only in the most phenotypically mature line (Jurkat). Global loss of PMA sensitivity in the nonresponders had not occurred because all $\mathrm{T}$ cell lines underwent phenotypic changes. Several hypotheses are suggested by these findings. Expression of the endothelial-binding lectin may be a late event in the developmental program of $T$ cells occurring shortly before or after Stage 3 thymocytes enter the recirculating lymphocyte pool. The simultaneous induction of phenotypic differentiation and upregulation of endothelial binding activity in Jurkat cells supports this conclusion. Such a linkage would explain the relative paucity of PNHEV adhesion receptors on normal $\mathrm{T}$ cell progenitors in bone marrow and postnatal thymus as well as their enrichment on late-stage, functionally mature cells in the adult murine thymus (5). Alternatively, the frequency of PNHEV binding activity in malignant $T$ cell lines may simply reflect the fact that relatively few $(1-3 \%$ in the murine thymus) thymocytes express functional PNHEV adhesion receptors. Malignant transformation of a cell with functional receptors, therefore, may be a rare event. Of course, intrinsic defects in the noninducible cell lines may preclude expression of binding activity or alter the response to PMA even if their thymic progenitors had the capacity to express the endothelial binding lectin. For this reason, cultured malignant cell lines can only be considered approximations of thymic subsets or discrete stages of normal development. Direct, multiparameter analysis of $T$ cell precursors is needed to further define the developmental regulation of the endothelial-binding lectin.

Hamann et al. recently demonstrated upregulation of the murine PNHEV receptor on mature, nodal lymphocytes during activation (38). Several current and published observations indicate that PMA treated Jurkat cells behave like stimulated postthymic lymphocytes raising the possibility that endothelial-binding activity in Jurkat cells, like that in murine lymphocytes, reflects activation rather than differentiation. Firstly, mitogens and PMA act synergistically to upregulate IL 2 receptor, IL 2, and $\gamma$ IFN synthesis in both Jurkat cells and PBMC $(39,40)$. Secondly, both Jurkat cells and PBMC downregulate surface antigens (CD3 and CD4) in response to PMA- and/or PHA-triggered, protein kinase C-mediated phosphorylation (34-36). Thirdly, normal resting lymphocytes respond to PMA with rapid, LFA1-dependent autoagglutination (41). We have observed both enhanced expression of LFA1 at the cell-surface (Table I) and autoagglutination (not shown) in Jurkat cells after 24-144 h of PMA treatment. The latter was completely inhibited by MAb TS1.18 to the LFAl beta subunit at $1 \mu \mathrm{g} / \mathrm{ml}$. Interestingly, Rothlein and Springer reported that the Jurkat line failed to agglutinate in response to PMA (41). This may reflect the phenotypic and functional heterogeneity of $T$ lymphoblastic lines maintained in continuous culture or differences in the duration of PMA treatment. In our experience, phorbol-induced agglutination of Jurkat cells varied significantly in different clonal isolates and was most pronounced after $24 \mathrm{~h}$ of incubation. Finally, the dramatic upregulation of CD2 observed in Jurkat cells during PMA stimulation (Table I) is analogous to that induced in cord-blood lymphocytes by PHA (37). Stimulated cordblood cells express CD2, CD18, and several other surface antigens at levels found on adult PBMC with the functional characteristics of memory lymphocytes. On the basis of these findings, Sanders et al. postulated that activation of virgin $T$ 

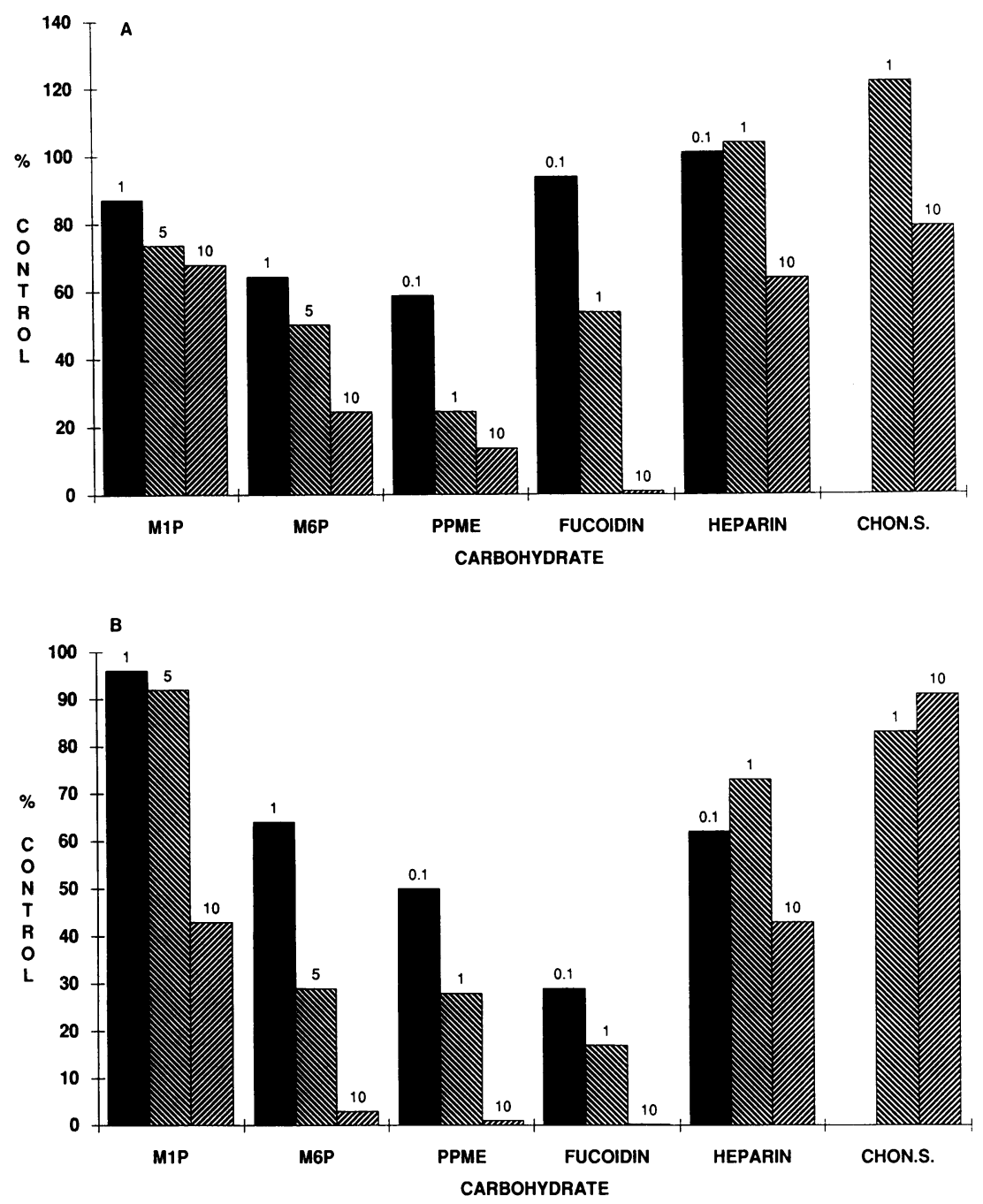

Figure 8. Inhibition of PMA-treated Jurkat cell interactions by carbohydrates. Standard HEV and PPME bead assays were performed after a $15-\mathrm{min}$ preincubation with carbohydrate at $4^{\circ} \mathrm{C}$. Carbohydrate was also present throughout the assay at the concentrations given above each bar. The concentrations for mannose-1-phosphate (M1P) and mannose-6-phosphate (M6P) are given in millimoles; the concentrations for $H$. holstii phosphomannan (PPME), fucoidin, heparin, and chondroitin sulfate (CHON.S.) are given in micrograms/milliliter. $(A)$ Inhibition of binding to the HEV of rat lymph nodes; $(B)$ inhibition of binding to PPME beads.

lymphocytes upregulates adhesion receptors that then augment immunologic activity. The phenotypic similarities between PHA-stimulated cord-blood lymphocytes and PMAtreated Jurkat cells raises the possibility that the PNHEV binding lectin may also be enhanced during this initial proliferative response. Phorbol stimulation of Jurkat cells thus initiates transcriptional, translational, and phenotypic changes observed in normal cells during both thymic differentiation and postthymic activation. The observed modulation of the endothelial-binding lectin, therefore, may be linked to one or both of these processes.

As detailed above, CD18 and CD2 are both upregulated in Jurkat cells after PMA treatment. These structures participate in a variety of lymphocytic adhesive interactions. The CD11a/CD18 heterodimer mediates, in part, the attachment of lymphocytes to cultured human microvascular endothelium (12-14), murine HEV (11) and a variety of antigen-independent adhesive interactions (42). MAbs to selected CD2 epitopes partially inhibit $\mathrm{T}$ cell attachment to accessory cells and targets; however, no effects on binding to endothelium have been reported $(42,43)$. The putative endothelial-binding lectin on Jurkat cells appears to be functionally distinct from these adhesion structures. MAbs to the CD18 (TS1.18) epitope failed to block Jurkat cell binding to either PPME beads or to paraformaldehyde-fixed PNHEV at $4.3 \mu \mathrm{g} / \mathrm{ml}$. At this concentration, TS1.18 inhibited phorbol-induced autoagglutination of Jurkat cells as well as the PMA-induced LFA I/ICAM1-dependent binding of normal lymphocytes to cultured keratinocytes (44). Furthermore, CD1 1a/CD18 mediated adhesion is magnesium dependent and most efficient at or above room temperature $(13,45)$. In contrast, PMA-stimulated Jurkat cells bound to PNHEV and PPME-beads in a calcium-dependent, magnesium-independent manner at low temperatures. The adhesive interaction between CD2 and its major endogenous ligand LFA3 is resistant to both EDTA and EGTA, distinguishing it from the lectin-mediated binding interactions of Jurkat cells (45). Finally, both normal human thymocytes (42, 46) and several of the $T$ lymphoblastic lines in the current study express significant levels of CD2 and CD1 la/18 but cannot bind to PNHEV in vitro. These adhesion structures alone, therefore, cannot account for Jurkat cell binding to PNHEV in the Stamper-Woodruff assay.

The lack of a CD18-sensitive component of PNHEV binding was surprising in light of recent murine studies documenting CD18-sensitive attachment to murine $\mathrm{HEV}$ in vitro and migration into nodes in vivo (11). Several explanations are possible. Firstly, the endothelial ligand for CD11a/CD18 may be sensitive to the paraformaldehyde fixation used in our stud- 
Table II. Expression of Hermes Epitopes on the Surface of Native and PMA-stimulated T Lymphoblastic Cell Lines

\begin{tabular}{ccccccc}
\hline Line & Treatment & HERM1 & HERM3 & PHERM & Lectin & HEV \\
\hline Jurkat & UT & 1 & 1 & 1,2 & $100(25)$ & $50(10)$ \\
& $72-144 \mathrm{~h}$ & 1 & 1 & 1,2 & $260(50)$ & $240(20)$ \\
Molt 4 & UT & 8 & 17 & & $10(3)$ & $15(5)$ \\
& $72-96 \mathrm{~h}$ & 25 & 34 & & $10(5)$ & $10(4)$ \\
CEM & UT & 25 & 34 & & $10(5)$ & $5(3)$ \\
& $72-96 \mathrm{~h}$ & 49 & 78 & & $7(3)$ & $5(3)$ \\
HSB-2 & UT & 7 & 22 & & $25(5)$ & $5(3)$ \\
& $72-96 \mathrm{~h}$ & 15 & 15 & & $10(5)$ & $5(3)$ \\
PBMC & UT & 5 & 13 & 18 & $100(10)$ & $100(15)$ \\
& & & & & & \\
\hline
\end{tabular}

The cell lines were grown in RPMI supplemented with 5-50 nM PMA for 72-144 h, then examined for expression of Hermes epitopes. UT, antigen expression in native (untreated) cell lines. HERM1 and HERM3 are MAbs raised in rat and mouse, respectively. PHERM is a polyclonal, mouse anti-human Hermes 1 heatinactivated whole antisera. The mean linear fluorescence intensity (see Table I and Methods), relative to the control reagents (purified rat IgG for HERM1, purified mouse IgG for HERM3, and whole nonimmune mouse sera for PHERM), in 5,000 cell samples are given for each antibody. Two different lots of nonimmune mouse serum were used as controls for PHERM. The mean and (SEM) for lectin expression and binding to PNHEV (taken from Figs. 4 and 2, respectively) are presented for comparison.

ies. Secondly, the CD11a/CD18 mediated adhesive interaction, particularly at low temperatures, may not be detected in a xenogenic assay system. Thirdly, the beta chain-specific reagent used in our studies may not react with or near the endothelial-binding domain of the heterodimer. Finally, Jurkat cells may use the endothelial binding lectin predominantly, despite expression of functional CD11a/CD18. In murine lymphomas, CD18 inhibits most effectively when the PNHEV adhesion-receptor is at low density (11). Direct quantization of lectin expression indicates that PMA-treated Jurkat cells express high levels of the endothelial-binding lectin, perhaps sufficient to maintain attachment to PNHEV despite blockade of CD11a/CD18-mediated interactions.

The murine peripheral node homing receptor-specific MAb Mel14 appears to cross-react antigenically with gp90 $0^{\text {Hermes }}(5-7)$. However, the Mel 14 and Hermes antigens differ in their linkage to carbohydrate- and endothelial-binding activities in intact cells. In the mouse, expression of the Mel 14 epitope, lectin activity, and affinity for PNHEV are coordinately regulated $(4,21)$. In the current series of human $T$ lymphoblastic malignancies, expression of several Hermes epitopes did not correlate with either lectin activity or binding to PNHEV. Because the murine LEC-CAM gp90 $0^{\text {Mel14 }}$ appears to mediate both carbohydrate and endothelial binding in the mouse (47), we suspect that the human homolog of $\mathrm{gp} 90^{\mathrm{Mel14}}$ is responsible for these activities in Jurkat cells. The absence of significant Hermes expression on Jurkat cells indicates that $\mathrm{gp} 90^{\text {Hermes }}$ is distinct from the human homologue of $\mathrm{gp} 90^{\text {Mell14}}$. Sequence analysis of $\mathrm{gp} 90^{\mathrm{Mel14}}(22,23,47)$ and several human Hermes/CD44 antigens demonstrates no significant homologies $(48,49)$. In light of the functional similarity between the murine and human endothelial binding lectins, it is reasonable to conclude that the human homologue of $\mathrm{gp} 90^{\mathrm{Mel} 14}$ and gp $90^{\text {Hermes }}$ are discrete membrane structures, each capable of mediating attachment to nodal HEV. Moreover, this study indicates that expression of Hermes epitopes on human lymphoid malignancies may not, in all cases, predict affinity for PNHEV. Quantitation of lectin expression and activity on intact cells thus will be crucial to clinical studies examining the role of endothelial adhesion in the spread of hematopoetic malignancies.

A principle target for PMA at the concentrations used in this study is protein kinase $C(50,51)$. Direct interaction with PKC, conversion of the cytoplasmic to the membrane-bound form and phosphorylation of selected membrane structures have been demonstrated in a variety of lymphoid cells (34-36, $52,53)$. Perturbation of the membrane by this lipophilic compound is cited as a potential non-specific action; however, such effects are unlikely at $<50 \mathrm{nM}(50,51)$ while upregulation of the endothelial-binding lectin occurs at $1 \mathrm{nM}$. PKC appears to function in both lymphocyte differentiation (27-29) and activation $(39,40)$. In conjunction with rapid mobilization of calcium, this enzyme provides a transmembrane signaling pathway for surface structures linked to phosphoinositol (52). In both normal lymphocytes and cultured lines, ligation of the $\mathrm{CD} 3 / \mathrm{Ti}$ receptor by lectins and cognate antigen activates the phosphoinositol pathway $(39,40)$. The Con A- and autologous MLR-induced modulation of HEV binding structures observed in the murine system thus may also involve PKC (54, 55). PMA-induced upregulation of the endothelial binding lectin, CD18 and CD2 in Jurkat cells further supports the hypothesis that PKC plays a pivotal role in regulating adhesion molecules mediating lymphocyte trafficking, sequestration in chronic inflammatory lesions and interactions with target cells. The coordinated modulation of these molecules in the Jurkat line provides a valuable tool for dissecting this regulatory process at the molecular level.

\section{Acknowledgments}

The authors thank Gregory Kleedke for his expert technical assistance; Dr. M. E. Slodki and Dr. M. Singer for their generous supply of PPME; Dr. E. C. Butcher for providing the Hermes-specific reagents; Dr. A. Krensky and Dr. C. Clayberger for providing the TS1.18 MAb; Dr. J. Varani and Dr. B. Nicholoff for sharing their experience with phorbol-induced adhesion events; and Dr. S. Rosen and Dr. T. Yednock for their thoughtful commentary and sage advice.

This work was supported by National Institutes of Health grant K08-CA00959-04 and American Cancer Society grant BC 466 to L. M. Stoolman.

\section{References}

1. Freemont, A. J., C. J. Jones, M. Bromley, and P. Andrews. 1983. Changes in vascular endothelium related to lymphocyte collections in diseased synovia. Arthritis. Rheum. 26:1427-1433.

2. Freemont, A. J., and W. L. Ford. 1985. Functional and morphological changes in post-capillary venules in relation to lymphocytic infiltration into BCG-induced granulomata in rat skin. J. Pathol. 147:1-12.

3. Freemont, A. J., and C. J. Jones. 1983. Light microscopic, histochemical and ultrastructural studies of human lymph node paracortical venules. J. Anat. 136:349-362.

4. Yednock, T. A., and S. D. Rosen. 1989. Lymphocyte homing. Adv. Immunol. 44:313-378. 
5. Berg, E. L., L. A. Goldstein, M. A. Jutila, M. Nakache, L. J. Picker, P. R. Streeter, N. W. Wu, D. Zhou, and E. C. Butcher. 1989. Homing receptors and vascular addressins: cell adhesion molecules that direct lymphocyte traffic. Immunol. Rev. 108:1-18.

6. Jalkanen, S., R. F. Bargatze, J. de los Toyos, and E. C. Butcher. 1987. Lymphocyte recognition of high endothelium: antibodies to distinct epitopes of an 85-95-kD glycoprotein antigen differentially inhibit lymphocyte binding to lymph node, mucosal, or synovial endothelial cells. J. Cell Biol. 105:983-990.

7. Jalkanen, S. P., R. Jalkanen, M. Bartgatze, M. Tammi, and E. C. Butcher. 1988. Biochemical properties of glycoproteins involved in lymphocyte recognition of high endothelial venules in man. J. Immunol. 141:1615.

8. Picker, L. J., M. J. de los Toyos, M. J. Telen, B. F. Haynes, and E. C. Butcher. 1989. Monoclonal antibodies against the CD44 [In(Lu)-related p80] and Pgp-1 antigens in man recognize the hermes class of lymphocyte homing receptors. J. Immunol. 142:2046-2051.

9. Holzman, B., B. W. McIntyre, and I. L. Weissman. 1989. Identification of a murine peyer's patch-specific lymphocyte homing receptor as an integrin molecule with an alpha-chain homologous to human VLA-4 alpha. Cell. 56:37-46.

10. Woodruff, J. J., L. M. Clarke, and Y. H. Chin. 1987. Specific cell-adhesion mechanisms determining migration pathways of recirculating lymphocytes. Annu. Rev. Immunol. 5:201-222.

11. Hamann, A., D. Jablonski-Westrich, K-L. Scholz, A. Duijvestijn, E. C. Butcher, and H-G. Thiele. 1988. I. Alterations in homing receptor expression and organ-specific high endothelial venule binding of lymphocytes upon activation. J. Immunol. 140:737-743.

12. Cavender, D., D. Haskard, C. L. Yu, T. Iguchi, P. Miossec, N. Oppenheimer Marks, and M. Ziff. 1987. Pathways to chronic inflammation in rheumatoid synovitis. Fed. Proc. 46:113-117.

13. Springer, T. A., M. L. Dustin, T. K. Kishimoto, and S. D. Marlin. 1987. The lymphocyte function-associated LFA-1, CD2, and LFA-3 molecules:cell adhesion receptors of the immune system. Annu. Rev. Immunol. 5:223-252.

14. Dustin, M. L., and T. A. Springer. 1988. Lymphocyte function-associated antigen-1 (LFA-1) interaction with intercellular adhesion molecule-1 (ICAM-1) is one of at least three mechanisms for lymphocyte adhesion to cultured endothelial cells. J. Cell Biol. 107:321-331.

15. Streeter, P. R., E. L. Berg, B. T. Rouse, R. F. Bargatze, and E. C. Butcher. 1988. A tissue-specific endothelial cell molecule involved in lymphocyte homing. Nature 331:41.

16. Streeter, P. R., B. Tien, N. Rouse, and E. C. Butcher. 1988. Immunohistologic and functional characterization of a vascular addressin involved in lymphocyte homing into peripheral lymph nodes. J. Cell Biol. 107:1853-1862.

17. Stoolman, L. M., and S. D. Rosen. 1983. Possible role for cell-surface carbohydrate-binding molecules in lymphocyte recirculation. J. Cell Biol. 96:722-729.

18. Stoolman, L. M., T. S. Tenforde, and S. D. Rosen. 1984. Phosphomannosyl receptors may participate in the adhesive interaction between lymphocytes and high endothelial venules. J. Cell Biol. 99:1535-1540.

19. Stoolman, L. M., T. A. Yednock, and S. D. Rosen. 1987. Homing receptors on human and rodent lymphocytes: evidence for a conserved carbohydrate-binding specificity. Blood. 70:1842-1850.

20. Yednock, T. A., L. M. Stoolman, and S. D. Rosen. 1987. Phosphomannosyl-derivatized beads detect a receptor involved in lymphocyte homing. J. Cell Biol. 104:713-723.

21. Yednock, T. A., E. C. Butcher, L. M. Stoolman, and S. D. Rosen. 1987. Receptors involved in lymphocyte homing: relationship between a carbohydrate binding receptor and the MEL-14 antigen. $J$. Cell Biol. 104:725-731.

22. Lasky, L. A., M. S. Singer, T. A. Yednock, D. Dowbenko, C. Fennie, H. Rodriguez, T. Nguyen, S. Stachel, and S. D. Rosen. 1989. Cloning of a lymphocyte homing receptor reveals a lectin domain. Cell. 56:1045-1055.
23. Siegelman, M., M. van de Rijn, and I. L. Weissman. 1989. Mouse lymph node homing receptor cDNA clone encodes a glycoprotein revealing tandem interaction domains. Science (Wash. DC). 243:1165-1172.

24. Rosen, S. D., M. S. Singer, T. A. Yednock, and L. M. Stoolman. 1985. Involvement of sialic acid on endothelial cells in organ-specific lymphocyte recirculation. Science (Wash. DC). 228:1005-1007.

25. Rosen, S. D., S.-I. Chi, D. D. True, M. S. Singer, and T. A. Yednock. 1989. Intravenously-injected sialidase inactivates attachment sites for lymphocytes on high endothelial venules. J. Immunol. 142:1895-1902.

26. Reinherz, E. L., P. C. Kung, G. Goldstein, R. H. Levey, and S. F. Schlossman. 1980. Discrete stages of human intrathymic differentiation:analysis of normal thymocytes and leukemic lymphoblasts of T-cell lineage. J. Cell. Physiol. 77:1588-1592.

27. Nagasawa, K., A. Howatson, and T. W. Mak. 1981. Induction of human malignant T-lymphoblastic cell lines MOLT-3 and jurkat by 12-O-tetradecanoylphorbol-13-acetate:biochemical, physical, and morphological characterization. J. Cell. Physiol. 109:181-192.

28. Delia, D., M. F. Greaves, R. A. Newman, D. R. Sutherland, J. Minowada, P. Kung, and G. Goldstein. 1982. Modulation of T leukaemic cell phenotype with phorbol ester. Int. J. Cancer. 29:23-31.

29. Carrel, S., J. P. Mach, G. Miescher, S. Salvi, L. Giuffre, M. Schreyer, and P. Isler. 1987. Phorbol 12-myristate 13-acetate induces surface expression of $\mathrm{T} 3$ on human immature cell lines with and without concomitant expression of the $\mathrm{T}$ cell antigen receptor complex. Eur. J. Immunol. 17:1079-1087.

30. Sangster, R. N., J. Minowada, N. Sucia-Foca, M. Minden, and T. W. Mak. 1986. Rearrangement and expression of alpha, beta and gamma chain of $\mathrm{T}$ cell receptor genes in human thymic leukemia cells and functional T cells. J. Exp. Med. 163:1491-1508.

31. Hara, J., S. H. Benedict, E. Champagne, T. M. Mak, M. Minden, and E. W. Gelfand. 1988. Comparison of T cell receptor alpha, beta, and gamma rearrangement and expression in $\mathrm{T}$ cell acute lymphoblastic leukemia. J. Clin. Invest. 81:989-966.

32. Wu, N. W., S. Jalkanen, P. R. Streeter, and E. C. Butcher. 1988. Evolutionary conservation of tissue-specific lymphocyte-endothelial cell recognition mechanisms involved in lymphocyte homing. J. Cell Biol. 107:1845-1851.

33. Lanier, L. L., J. P. Allison, and J. H. Phillips. 1986. Correlation of cell surface antigen expression on human thymocytes by multi-color flow cytometric analysis: implications for differentiation. J. Immunol. 137:2501-2507.

34. Cantrell, D. A., A. A. Davies, and M. J. Crumpton. 1985. Activators of protein kinase $C$ down-regulate and phosphorylate the T3/T-cell antigen receptor complex of human T lymphocytes. Proc. Natl. Acad. Sci. USA. 82:8158-8162.

35. Davies, A. A., D. A. Cantrell, J. M. Hexham, P. J. Parker, J. Rothbard, and M. J. Crumpton. 1987. The human T3 gamma chain is phosphorylated at serine 126 in response to $\mathrm{T}$ lymphocyte activation. J. Biol. Chem. 262:10918-10921.

36. Acres, R. B., P. J. Conlon, D. Y. Mochizuki, and B. Gallis. 1986. Rapid phosphorylation and modulation of the T4 antigen on cloned helper T cells by phorbol myristate acetate or antigen. J. Biol. Chem. 261:16210-16214.

37. Sanders, M. E., M. W. Makgoba, S. O. Sharrow, D. Stephany, T. A. Springer, H. A. Young, and S. Shaw. 1988. Human memory T lymphocytes express increased levels of three cell adhesion molecules (LFA-3, CD2, and LFA-1) and three other molecules (UCHL1, CDw29, and Pgp-1) and have enhanced IFN-gamma production. $J$. Immunol. 140:1401-1407.

38. Hamann, A., D. Jablonski-Westrich, K-L. Scholz, A. Duijvestijn, E. C. Butcher, and H. G. Thiele. 1988. I. Alterations in homing receptor expression and organ-specific high endothelial venule binding of lymphocytes upon activation. J. Immunol. 140:737-743.

39. Weiss, A., J. Imboden, K. Hardy, B. Manger, C. Terhorst, and J. Stobo. 1986. The role of the T3/antigen receptor complex in T-cell activation. Annu. Rev. Immunol. 4:593-619. 
40. Weiss, A., and J. B. Imboden. 1987. Cell surface molecules and early events involved in human T lymphocyte activation. $A d v$. Immunol. 41:1-38.

41. Rothlein, R., and T. A. Springer. 1986. The requirement for lymphocyte function-associated antigen 1 in homotypic leukocyte adhesion stimulated by phorbol ester. J. Exp. Med. 163:1132-1149.

42. Bierer, B. E., and S. J. Burakoff. 1988. T-cell adhesion molecules. FASEB (Fed. Am. Soc. Exp. Biol.) J. 2:2584-2590.

43. Haynes, B. F., B. J. Grover, L. P. Whichard, L. P. Hale, J. A. Nunley, D. E. McCollum, and K. H. Singer. 1988. Synovial microenvironment-T cell interactions. Human $\mathrm{T}$ cells bind to fibroblast-like synovial cells in vitro. Arthritis Rheum. 31:947-955.

44. Nickoloff, B. J., and R. S. Mitra. 1988. Phorbol ester treatment enhances binding of mononuclear leukocytes to autologous and allogeneic gamma-interferon-treated keratinocytes, which are blocked by anti-LFA-1 monoclonal antibody. J. Invest. Dermatol. 90:684-689.

45. Shaw, S., G. E. Luce, R. Quinones, R. E. Gress, T. A. Springer, and M. E. Sanders. 1986. Two antigen-independent adhesion pathways used by human cytotoxic T-cell clones. Nature (Lond.). 323:262-264.

46. Jalkanen, S. T., and E. C. Butcher. 1985. In vitro analysis of the homing properties of human lymphocytes: developmental regulation of functional receptors for high endothelial venules. Blood. 66:577582.

47. Stoolman, L. M. 1989. Adhesion molecules controlling lymphocyte migration. Cell. 56:907-910.
48. Goldstein, L. A., D. F. H. Zhou, L. J. Picker, C. N. Minty, R. F. Bargatze, J. F. Ding, and E. C. Butcher. 1989. A human lymphocyte homing receptor, the hermes antigen, is related to cartilage proteoglycan core and link proteins. Cell. 56:1063-1072.

49. Stamenkovic, I., M. Amiot, J. M. Pesando, and B. Seed. 1989. A lymphocyte molecule implicated in lymph node homing is a member of the cartilage link protein family. Cell. 56:1057-1062.

50. Kikkawa, U., and Y. Nishizuka. 1986. The role of protein kinase C in transmembrane signalling. Annu. Rev. Cell Biol. 2:149158.

51. Nishizuka, Y. 1984. The role of protein kinase $C$ in cell surface signal transduction and tumour promotion. Nature (Lond.). 308:693698.

52. Kaibuchi, K., Y. Takai, and Y. Nishizuka. 1988. Protein kinase $\mathrm{C}$ and calcium ion in mitogenic response of macrophage-depleted human peripheral lymphocytes. J. Biol. Chem. 260(3):1366-1369.

53. Yamamoto, Y., T. Ohmura, K. Kawakami, K. Onoue, and H. Hidaka. 1986. Induction and regulation of human interleukin 2 gene expression: significance of protein kinase $\mathrm{C}$ activation. J. Biochem. 100:333-340.

54. Dailey, M. O., C. G. Fathman, E. C. Butcher, E. Pillemer, and I. Weissman. 1982. Abnormal migration of $\mathrm{T}$ lymphocyte clones. $J$. Immunol. 128:2134-2136.

55. Jung, T. M., W. M. Gallatin, I. L. Weissman, and M. O. Dailey. 1989. Down regulation of homing receptors after $T$ cell activation. $J$. Immunol. 141:4110-4117. 